\title{
A crise do sistema financeiro globalizado contemporâneo: perspectivas a partir da reforma regulatória global pós-2008
}

\author{
The crisis of the contemporary global financial system: \\ perspectives from the post-2008 global regulatory reform
}

NORBERTO MONTANI MARTINS*;**

\begin{abstract}
RESUMO: O artigo analisa como a reforma regulatória implantada após a crise financeira internacional de 2008 afetou os processos estruturantes do sistema financeiro globalizado. Argumentamos que a reforma buscou re-regular os mercados financeiros, redefinir a estrutura e as bases do modelo de negócios dos bancos globais, influenciando a questão da intermediação, e limitar a capacidade de externalização do risco e de alavancagem das instituições e do sistema como um todo. Concluímos que as mudanças regulatórias, embora tímidas em alguns tópicos, influenciaram os processos estruturantes do sistema financeiro global e alteraram, menos pronunciadamente, seu modus operandi e suas bases de expansão. PALAVRAS-CHAVE: Sistema financeiro global; crise financeira internacional; regulação financeira.
\end{abstract}

ABSTRACT: The present paper analyses how the regulatory reform that followed the 2008 international financial crisis influenced the processes that structured the contemporary global financial system. We argue that the reform aimed to re-regulate financial markets, change global banking business models, and limit financial institutions' ability to externalize risks and leverage. Our conclusions point out that regulatory changes, albeit timid in some areas, were able to influence the processes that structured the global financial system and then changed its modus operandi and possibilities for expansion.

KEYWORDS: Global Financial system; international financial crisis; financial regulation. jEL Classification: E44; F65; G15; N20.

\footnotetext{
* Doutorando do Programa de Pós-Graduação em Economia do Instituto de Economia da Universidade Federal do Rio de Janeiro, Rio de Janeiro/RJ, Brasil. E-mail: norberto.montani@gmail.com. Submetido: 19/Julho/2016; Aprovado: 22/Março/2018.

* O autor é bolsista da Fundação Carlos Chagas Filho de Amparo à Pesquisa do Estado do Rio de Janeiro.
} 


\section{INTRODUÇÃO}

$\mathrm{Na}$ edição de julho-setembro de 2014 desta Revista de Economia Política foi publicado o artigo intitulado "A crise do sistema financeiro globalizado contemporâneo", de autoria do professor Ernani Torres. Neste texto, o autor analisa a evolução da globalização financeira e descreve os processos - ou vertentes - que estruturaram o chamado sistema financeiro globalizado contemporâneo, nomeadamente: a liberalização dos mercados financeiros, a desintermediação bancária, a externalização do risco e a elevada alavancagem.

O autor argumenta que a crise de 2008 representou "um choque de grandes proporções para o sistema financeiro globalizado". Teve efeitos sobre o núcleo deste sistema, qual seja, o sistema financeiro americano, e provocou uma mudança de trajetória do processo de expansão e diversificação de ativos inaugurado na década de 1980. Além disso, os elevados níveis de alavancagem e endividamento das instituições financeiras foram questionados abertamente: não seria mais sustentável manter o sistema operando nestes termos.

Desde 2008, uma série de medidas foram tomadas para redefinir o espaço de operação do sistema financeira globalizado. O G20 firmou compromisso com uma profunda reforma regulatória, que manifesta as regras do jogo do sistema. Criou-se um Comitê de Estabilidade Financeira, responsável por coordenar os esforços de reforma; foi criada uma ampla agenda de mudanças regulatórias a ser implementada pela Organização das Comissões de Valores (Iosco) e pelo Comitê de Basileia, dentre outros organismos internacionais; e os Estados Unidos aprovaram a chamada Lei Dodd-Frank, que revisita uma série de aspectos da regulação do sistema financeiro no país.

Torres não avança sobre estes temas em seu artigo, que tem seus limites fixados à descrição da montagem do sistema financeiro global contemporâneo e da análise de como a crise, ali gestada, atuou sobre o mesmo. Aqui buscamos dar continuidade à sua explanação incorporando novos elementos à sua análise: buscamos avaliar como as mudanças regulatórias do pós-crise influenciam os processos estruturantes do sistema financeiro global e, assim, afetam sua configuração e as bases para a reestruturação desse sistema - um processo ainda em curso.

Segundo nossa perspectiva, a regulação permeia todos os processos ou vertentes estruturantes discutidas por Torres (2014). Os esforços regulatórios do pós-crise têm efeito direto e imediato sobre a questão da liberalização dos mercados, já que representam uma tentativa de adicionar amarras aos mercados liberalizados característicos do sistema financeiro global. É também através da regulação que as autoridades buscam influenciar a estrutura dos sistemas financeiros e o modelo de negócios através dos quais as transações financeiras são realizadas, assim, induzindo as tendências de desintermediação ou intermediação das transações financeiras. Além disso, as regulações desenhadas após a crise buscam determinar uma maior internalização dos riscos e impor limites à alavancagem das instituições e, em última instância, do sistema como um todo.

As seções a seguir analisam esses tópicos, na ordem aqui elencada. As quatro 
vertentes analisadas por Torres são desfiguradas e reorganizadas para refletir a ordem aqui delineada, sendo mediadas, a todo momento, pela apresentação das medidas regulatórias. Segue-se a esta apresentação uma discussão crítica das mudanças, que busca avaliar em que medida as mudanças apresentadas afetaram, de fato, o status quo e alteraram o modo pelo qual o sistema financeiro global se estrutura e opera. Por fim, delineia-se um conjunto de considerações finais, confrontando a análise das mudanças regulatórias e a perspectiva crítica apresentada.

\section{"RE-REGULAÇÃO": UMA VISÃO GERAL DAS MUDANÇAS REGULATÓRIAS PÓS-2008}

Exatamente um mês após a quebra, em 15 de setembro de 2008, do banco norte-americano Lehman Brothers, os líderes das principais economias do mundo se reuniram no encontro de cúpula do G20, em Washington. O abalo nos sistemas financeiros e nas economias de diversos países gerado pela quebra da instituição financeira norte-americana foi de proporções sísmicas. Naquele momento, nem o tamanho, nem a duração da crise que era inaugurada eram minimamente delineáveis. Um plano de ação para lidar com a debacle mundial era mais que necessário.

A declaração que seguiu ao encontro é enfática em um ponto: era necessário prosseguir com os esforços e tomar quaisquer ações que fossem julgadas necessárias para estabilizar o sistema financeiro. Entretanto, estes esforços estavam muito aquém do que era considerado suficiente pelos líderes do G20. Já nesta primeira reação, sinaliza-se que uma profunda reforma financeira deveria ser realizada. Firma-se o compromisso: "nós implementaremos reformas que fortalecerão os mercados financeiros e os regimes de regulação, de forma a evitar crises futuras" (G20, 2008: $\$ 8$ ).

Nesta linha, foram acordados princípios comuns para a reforma dos sistemas financeiros. A palavra "comum" neste caso se refere a um esforço coordenado dos países envolvidos, portanto uníssono, já que as autoridades reconheciam a soberania dos reguladores nacionais em suas jurisdições. Contudo, para lidar com um sistema financeiro globalizado, a coordenação e a definição de diretrizes internacionais se faziam necessárias para proteger o sistema internacional "contra desenvolvimentos transnacionais, regionais e globais adversos, impactando a estabilidade financeira internacional" (idem).

Cinco eram os princípios: fortalecimento da transparência e responsabilidade; criação de padrões sólidos de regulação; promoção da integridade dos sistemas financeiros; fortalecimento da cooperação internacional; e, reforma das instituições financeiras internacionais, como o Fundo Monetário Internacional (FMI).

O segundo princípio, em particular, é de notável interesse à nossa arguição:

Comprometemo-nos a fortalecer nossos regimes regulatórios, nossa supervisão prudencial e gerenciamento de riscos e a assegurar que todos os mercados financeiros, produtos e participantes estejam regulados ou sujeitos à supervisão, de acordo com as circunstâncias. Exerceremos super- 
visão rigorosa sobre as agências de classificação de risco, em consonância com o código de conduta internacional acordado e fortalecido. Também tornaremos os regimes regulatórios mais eficazes ao longo do ciclo econômico, assegurando eficiência na regulação, para que a inovação não seja reprimida e haja incentivo à expansão do comércio em produtos e serviços financeiros. Comprometemo-nos a assegurar que as avaliações de nossos sistemas nacionais regulatórios sejam transparentes. (G20, 2008: \$9)

Desta afirmativa podemos inferir a sinalização de que o processo de liberalização dos mercados financeiros passaria por uma mudança de trajetória. Ou seja, veríamos inaugurado um período de re-regulação dos mercados financeiros, cujo ímpeto e profundidade não seriam predeterminados.

O pontapé inicial da reforma regulatória enfocou as agências de notação de risco, cujo modus operandi ficou caracterizado por gritantes conflitos de interesse, o mercado de derivativos de crédito, extremamente opaco e que funcionou como importante canal de contágio, e o monitoramento da capitalização das instituições. Estas seriam medidas de curtíssimo prazo, a serem levadas a cabo num período de três a quatro meses. Outro ponto inicial foi a promoção de uma revisão dos padrões de gerenciamento de risco das instituições financeiras, que a eclosão da crise revelou extremamente frouxos. Tais medidas foram fixadas no Plano de Ação para Implantação dos Princípios para Reforma, anexo à declaração da cúpula de Washington.

Em abril de 2009, a cúpula do G20 se reuniu novamente em Londres. $\mathrm{Na}$ ocasião, as reformas propostas avançaram em novas (e diversas) frentes. Criou-se o Comitê de Estabilidade Financeira (Financial Stability Board ou FSB, na sigla em inglês), com um mandato amplo e reforçado em comparação à entidade que o precedeu, o Fórum de Estabilidade Financeira. Ao FSB caberia a responsabilidade de coordenação e troca de informações entre as autoridades nacionais para a promoção da estabilidade financeira global, além de coordenar e acompanhar, de modo geral, as diversas reformas regulatórias a serem implantadas. A constante avaliação de vulnerabilidades no sistema financeiro global e a identificação de formas de ação para mitiga-las também foram atribuídas ao Comitê (Helleiner, 2014: 109-13).

O mandato para alteração dos padrões de regulação bancária também foi fixado neste encontro. O Comitê de Basileia ficou responsável por estabelecer colchões de capital e implementar medidas para aumentar a qualidade do capital das instituições financeiras, assim que a recuperação econômica se delineasse de forma mais clara. Novas regras para securitização e a construção de requerimentos de alavancagem também foram demandadas pelas autoridades do G20 - voltaremos a estes pontos mais adiante. A necessidade de um novo acordo de Basileia, o terceiro, começa a surgir de forma mais estruturada neste ponto.

Outro aspecto importante que aparece pela primeira vez nas declarações do G20 foi o acordo em "estender a regulação e a supervisão a todas as instituições financeiras sistemicamente importantes, instrumentos e mercados”, incluindo aí os fundos de hedge de atuação global (G20, 2009: \$15). O vácuo regulatório de alguns 
segmentos ficou patente com a crise. Os líderes do G20 acordaram que os fundos de hedge precisavam ser registrados, regulados e monitorados, oferecendo maior transparência à avaliação dos riscos colocados por estas entidades para os reguladores e a sociedade em geral. Também incluíram neste rol de entidades todas aquelas que pudessem ser identificadas como "sistemicamente importantes".

Noutra frente, deu-se atenção aos padrões de remuneração e compensação dos executivos e empregados do sistema financeiro. Os elevados bônus pagos aos altos executivos de instituições financeiras antes e em meio à crise geraram situações constrangedoras para as autoridades, responsáveis por salvar as instituições. A revisão destes padrões e o realinhamento de incentivos dos empregados de instituições financeiras consistiu em um objetivo relevante.

Por fim, mas não menos importante, firmou-se o compromisso de "atuar contra jurisdições não cooperativas, inclusive paraísos fiscais". As autoridades do G20 fazem um discurso extremamente duro contra a evasão fiscal e a lavagem de dinheiro: "Estamos prontos para aplicar sanções com vistas a proteger nossas finanças públicas e sistemas financeiros. A era de sigilo bancário acabou" (G20, 2009: \$15). O Grupo de Ação Financeira foi chamado a reforçar os padrões para prevenção de lavagem de dinheiro e financiamento ao terrorismo e tornar mais rigoroso o processo de avaliação e credenciamento das jurisdições.

As medidas de abril de 2009 foram depois complementadas por outros tópicos nas seguidas reuniões de cúpula do G20. Uma completa descrição destas medidas para a reforma regulatória do sistema financeiro vai além do escopo deste artigo, mas não podemos deixar de destacar: a reforma dos padrões de operação e gerenciamento de risco das infraestruturas de mercado; a revisão dos mecanismos de resolução de instituições quebradas (intervenção e falência); a revisão dos benchmarks financeiros (após o escândalo da taxa Libor); e, com o mesmo intuito da regulação dos hedge funds, a regulação do chamado sistema bancário paralelo (shadow banks).

A reforma iniciada em 2009 deu origem a uma série de mudanças nos padrões internacionais, bem ilustradas por Basileia III, a nova regulação do mercado global de derivativos de balcão e os novos Princípios para Infraestrutura de Mercado Financeiro. Estes novos padrões, por sua vez, foram transpostos, de forma mais ou menos fiel, para os arcabouços nacionais num extenso trabalho jurídico.

É importante notar que não só respostas coordenadas no G20 foram geradas à crise, mas diversas iniciativas foram gestadas e implementadas em nível nacional. O caso mais emblemático é o da Lei Dodd-Frank, de 2009, nos Estados Unidos, que trouxe alterações regulatórias nas mais diversas áreas e reforçou o arcabouço norte-americano. Várias das mudanças previstas por esta Lei foram contempladas no conjunto de mudanças planejadas em nível global.

Sem discutir mais a fundo todas as mudanças levadas a cabo, o fato estilizado, se assim quisermos chamar, é que a crise de 2008 deu origem a um período de mudança de trajetória do processo de flexibilização regulatória vigente desde os anos 1980. O tom pós-2008 foi de re-regulação dos mercados, maior rigor regulatório, criação de mais amarras à operação do sistema financeiro global. Mesmo a 
utilização de controles de capitais passou a ser novamente admitida em algumas situações - ver FMI (2011) -, revertendo a demonização deste instrumento no período anterior e criando, relativamente, um ambiente de menor liberdade de movimentação dos recursos entre as fronteiras das jurisdições.

\section{O MODELO DE NEGÓCIOS DOS BANCOS REVISITADO}

Conforme aponta Torres (2014: 42-3), a formação do sistema financeiro globalizado foi marcada pela reestruturação do modelo de negócios dos bancos norte-americanos. O modelo compartimentalizado estabelecido no pós-crise de 1929, com bancos comerciais, bancos de investimento, corretoras etc., em unidades segmentadas, deu lugar à centralização das operações em bancos “universais” e conglomerados. A securitização se desenvolveu amplamente, criando um novo modelo de originar para distribuir ${ }^{1}$, e o mercado de capitais, incluindo aí o mercado de derivativos financeiros, passou a ser cada vez mais relevante no cotidiano das instituições bancárias. Como sintetizado por Kregel (2008: 5), este novo sistema bancário "was based on the ability of the banks' proprietary trading desks to generate profits, and on affiliates to produce fee and commission income".

Em paralelo, e como parte do processo de reconfiguração do sistema bancário norte-americano, testemunhou-se uma nova onda de concentração e internacionalização das instituições, em especial, as norte-americanas, que operaram para plugar os sistemas financeiros de países periféricos a Nova York e estreitar os laços com outros centros financeiros internacionais, originando então o sistema financeiro globalizado na forma que conhecemos.

A eclosão da crise de 2008 trouxe à tona as vulnerabilidades do novo modelo de operação das instituições financeiras. A leitura do G30, um grupo consultivo formado por ex-presidentes de bancos centrais e acadêmicos, sobre o que ocorreu aponta algumas vulnerabilidades na nova configuração:

Recent experience in the United States and elsewhere has demonstrated instances in which unanticipated and unsustainably large losses in proprietary trading, heavy exposure to structured credit products and credit default swaps, and sponsorship of hedge funds have placed at risk the viability of the entire enterprise and its ability to meets its responsibilities to its clients, counterparties, and investors. (G30, 2009: 27)

\footnotetext{
${ }^{1}$ Conforme descrito por Kregel (2008: 11), nesta nova forma de operação o banco "seeks to maximize its fee and commission income from originating assets, managing those assets in off-balance-sheet affiliate structures, underwriting the primary distribution of securities collateralized with those assets, and servicing them. Under this system, the banker has no interest in credit evaluation, since the interest and principal on the loans originated will be repaid to the final buyers of the collateralized assets".
} 
Com este diagnóstico em mente, as mudanças regulatórias após 2008 buscaram fazer frente aos desafios impostos pelo novo modelo de negócios dos bancos.

Nos Estados Unidos, a Lei Dodd-Frank dedicou uma seção à instituição da chamada Regra de Volcker - cujos primeiros traços são delineados no documento do G30 mencionado acima, que contou com a participação do ex-presidente do banco central norte-americano, Paul Volcker. A norma tem dupla intencionalidade: proibir a negociação proprietária de instituições financeiras que captam depósitos junto ao público, i.e., bancos; vedar o estabelecimento de relacionamentos entre os bancos e fundos de hedge e private equity. No primeiro caso, busca-se dirimir conflitos de interesse e limitar os riscos incorridos pelas tesourarias dos bancos, que acabam sendo repassados (direta ou indiretamente) aos seus depositantes. No segundo caso, além dos dois objetivos anteriores, busca-se evitar o contágio e a operação de salvamento de fundos arriscados com recursos proprietários ${ }^{2}$.

A Regra de Volcker acaba por induzir na prática uma segmentação das atividades bancárias. A instituição que capta depósitos tem duas opções: abandonar o modelo "originar para distribuir" ou segmentá-lo numa estrutura legal à parte, que não se confunda com o core business do banco comercial, ainda que sob o mesmo controlador. É como se a Regra operasse segmentando bancos comerciais e de investimento, porém estabelecendo uma linha mais tênue entre estas categorias.

A proibição da relação com fundos de hedge e private equity também tem função importante, pois as tesourarias, teoricamente, se veriam obrigadas a não mais operar através destas estruturas ou segundo a forma de relacionamento incestuosa que frequentemente mantinham com as mesmas. Induz-se, portanto, à separação das atividades de gestão destes fundos das demais atividades da instituição financeira.

No Reino Unido e na Europa também foram editadas regras que tinham efeitos similares à norte-americana, contudo, numa roupagem diferente. $\mathrm{O}$ chamado ringfencing dos bancos britânicos e europeus prevê a separação (legal) das instituições que captam recursos por meio de depósitos e a definição das operações que estão autorizadas a realizar, estimulando a criação de instituições segmentadas de acordo com suas funções nucleares (Anbima, 2012).

Outro aspecto que complementa as regras acima descritas é a regulação sobre o chamado sistema bancário paralelo (shadow banking). No modelo "originar para distribuir”, cadeias cada vez mais complexas de relações e instituições financeiras foram estruturadas para viabilizar a originação de ativos em meio ao ambiente extremamente competitivo da globalização financeira (Pozsar et al., 2010).

\footnotetext{
${ }^{2}$ A lógica da Regra de Volcker segue à risca a recomendação ${ }^{\circ} 1$ do relatório do G30 sobre reforma financeira: "Large, systemically important banking institutions should be restricted in undertaking proprietary activities that present particularly high risks and serious conflicts of interest. Sponsorship and management of commingled private pools of capital (that is, hedge and private equity funds in which the banking institutions own capital is commingled with client funds) should ordinarily be prohibited and large proprietary trading should be limited by strict capital and liquidity requirements. Participation in packaging and sale of collective debt instruments should require the retention of a meaningful part of the credit risk" (G30, 2009: 28).
} 
Uma série de relações e agentes com padrões regulatórios mais baixos que os do sistema bancário tradicional (e às vezes mesmo inexistentes) passaram a integrar o sistema. Fundos de curtíssimo prazo, os chamados money market funds, passaram a competir com os bancos pelos "depósitos" e outras instituições e práticas ganharam corpo à sombra da regulação estabelecida. Dentre as práticas, a já mencionada securitização e as operações compromissadas e de empréstimo de ativos se tornaram corriqueiras como meio para obter recursos para financiar as operações.

A elevação do risco de contágio nesta nova configuração era patente, em semelhança às relações dos bancos com fundos de hedge mencionadas acima. Para mitigar tais problemas e trazer estas práticas e instituições para os holofotes dos reguladores, o FSB iniciou uma frente para a regulação deste sistema paralelo para detalhes, ver Anbima (2013).

A partir das regras de separação e banimento do trading proprietário e da regulação sobre o shadow banking system, o processo de estreitamento dos laços entre bancos e mercado de capitais passou a ser revisitado, com uma nova regulação incidindo em áreas antes pouco exploradas (ou mesmo inexploradas) pelas autoridades e limitando a imbricação das relações entre mercados de capitais e bancos.

Os novos termos sobre os quais as instituições financeiras se viram obrigadas a operar e os elevados custos dos novos requerimentos regulatórios acabaram por ter, ainda, um efeito sobre o escopo geográfico de alguns mercados e operações. Por um lado, o processo que podemos chamar de "re-segmentação", encarece o trading proprietário e gera uma revisão das posições em diferentes espaços geográficos. Por outro lado, o maior custo regulatório impõe uma reavaliação da relação custo-benefício, com destaque para os custos de observância (compliance), das operações das instituições e das relações transfronteiriças estabelecidas. Resulta daí a balcanização de alguns mercados e operações.

Dois exemplos deste processo podem ser mencionados. Os novos padrões, mais rigorosos, de prevenção à lavagem de dinheiro e financiamento ao terrorismo deram origem a um processo conhecido como de-risking ou "diminuição dos riscos", em tradução livre, que consiste na supressão de relações entre instituições dos países centrais, em particular, Estados Unidos, e países menores, com maiores riscos de lavagem (ao menos, em potencial) - o de-risking também se refere à recusa e supressão de relações com determinados clientes (grupos ou nacionalidades).

Como apontam Canuto e Ramcharan (2015): "Small states, like the Caribbean countries, have been negatively affected by recent 'de-risking' policies implemented by international banks, with particularly damaging consequences on correspondent banking relationships". As elevadas multas que importantes bancos internacionais foram obrigados a pagar por infrações ligadas à lavagem de dinheiro serviram como fator desencadeador do processo de diminuição do risco. Para ficar em um só exemplo, em 2012, o HSBC foi multado em US\$1,9 bilhões por falhas no controle de quase US\$ 1 bilhão em operações de tráfico de drogas e transações realizadas com Irã, Líbia e Sudão (Wall Street Journal, 2015; Business Insider UK, 2015).

Já a nova regulação do mercado de derivativos de balcão, que passou a olhar 
para instituições sistemicamente importantes, gerou como resposta a concentração das operações em mercados específicos. Em particular, a nova regulação norte-americana requer que instituições que negociem grandes volumes de derivativos com contrapartes norte-americanas, independentemente do mercado onde se processe o contrato, se registrem como swap dealers e cumpram uma série de obrigações, com elevados custos de compliance. Como forma de evitar vários registros, de unidades de diferentes países, as instituições financeiras internacionais passaram a concentrar suas operações em determinadas jurisdições - e, assim, reduzir o número de registros necessários.

Uma pesquisa publicada pela Associação Internacional de Derivativos e Swaps (Isda) em 2014 aponta a fragmentação da liquidez dos mercados de derivativos, que registraram uma queda nos negócios transfronteiriços e passaram a se concentrar nacional ou regionalmente após a entrada em vigor dos novos dispositivos regulatórios nos Estados Unidos. Como explicitado no relatório da entidade, o mercado passou por certa balcanização: "Trading between US persons and non-US persons has declined. Most notably, fragmentation is disrupting the market for Euro interest rate swaps as liquidity pools have become more exclusive amongst European dealers" (Isda, 2014: 9). Dados atualizados em 2015 reforçaram o diagnóstico (Isda, 2015).

Além dos dois exemplos acima acerca do processo de balcanização, podemos destacar a venda de algumas unidades importantes de bancos internacionais em mercados menores, contudo sem o caráter sistemático dos processos descritos anteriormente. A venda da unidade colombiana do Santander para o banco chileno CorpBanca (Financial Times, 2011), a venda da unidade brasileira do HSBC para o Bradesco (Reuters, 2015) e a recente notícia de que o Citigroup pretende vender suas operações de varejo em Argentina, Brasil e Colômbia (Bloomberg, 2016) sugerem mudanças nas estratégias das instituições internacionais (ao menos, na região).

À guisa de síntese, podemos afirmar que o modelo de negócios dos grandes bancos globais vem sendo revisitado através das regras de proibição ou separação de negociação proprietária e os novos custos regulatórios, em sentido amplo, contribuem para uma reconfiguração do processo de internacionalização vivenciado anteriormente. Estes dois fatos estilizados, que podemos chamar de "re-segmentação" e "re-nacionalização", são produtos diretos das mudanças regulatórias pós-2008.

Contudo, esses fatos não buscaram alterar o modo através do qual as instituições realizam suas operações e tampouco limitar sua participação nos mercados.

\section{COLCHÕES DE SEGURANÇA: DA EXTERNALIZAÇÃO À INTERNALIZAÇÃO DOS RISCOS}

A terceira característica do sistema financeiro global destacada por Torres (2014: 447) diz respeito à externalização do risco, isto é, a mercantilização e a redistribuição de risco entre os diferentes investidores através dos já mencionados 
mecanismos de securitização, derivativos, operações compromissadas e empréstimos de ativos (securities lending).

Neste caso, o desenvolvimento regulatório pós-crise não buscou proibir a utilização destes mecanismos, mas sim torná-los mais seguros para as contrapartes das operações. As reformas foram desenhadas, portanto, para mitigar o risco sistêmico e as possibilidades de contágio originadas nos mercados destes instrumentos. Ainda, com a regulação das agências de classificação de risco, buscou-se dirimir os conflitos de interesse envolvidos nos processos de externalização dos riscos.

No caso da securitização, as reformas avançaram em três frentes: (i) padronização dos instrumentos; (ii) aumento da transparência; (iii) adoção de requerimentos de retenção de risco ("skin in the game" requirements, na expressão em inglês). $\mathrm{O}$ aumento da padronização e a transparência dizem respeito, basicamente, à provisão e divulgação de informações sobre os ativos securitizados de modo inteligível e sistematizado para reguladores e participantes de mercado. Já o terceiro tópico representa um constrangimento ao modelo "originar para distribuir": ao fazer com que o originador retenha uma parte do risco do ativo securitizado, busca-se elevar os padrões de avaliação de risco de crédito. Com isso, o originador é obrigado a "internalizar" parte do risco gerado por seu ativo. Ao colocar a pele dos originadores em risco, os reguladores acreditam que o sistema terá uma base mais segura para sua operação (Iosco, 2012; BCBS, 2012).

No caso das operações de empréstimo de títulos e compromissadas, as mudanças regulatórias enfocaram, além da padronização e da transparência, as práticas de reutilização de garantias (rehypothecation) e o estabelecimento de haircuts nas operações. A reutilização de garantias se refere ao processo através do qual uma mesma garantia é utilizada para lastrear uma cadeia de operações ou diferentes operações não relacionadas. Com a reutilização, o sistema pode operar com elevada alavancagem sobre uma base de ativos líquidos mais restrita. Já os haircuts são margens aplicadas aos (abatidas dos) valores dos ativos emprestados ou lastro de operações compromissadas com o objetivo de assegurar parte da remuneração caso o valor de mercado dos ativos de referência caia. É uma espécie de colchão de segurança perante o risco de mercado. Naturalmente, quanto maior o risco de mercado, maiores os haircuts exigidos pelos ofertantes de títulos nestes mercados, o que limita a liquidez destas operações.

Os aprimoramentos regulatórios implantados tiveram como objetivo limitar a reutilização de garantias, impondo restrições explícitas às possibilidades de reuso de colateral. Com isso, busca-se aumentar os colchões de segurança (liquidez) do sistema, reduzindo as possibilidades de alavancagem sobre uma dada base de ativos líquidos. Já no caso dos haircuts, buscou-se estabelecer padrões mínimos que operassem para reduzir a pró-ciclicidade destes descontos. A utilização de infraestruturas de mercado que garanta a liquidação das operações (ao menos numa ponta), como contrapartes centrais, no caso das transações mais padronizadas também foi uma linha utilizada pelos reguladores.

Contrapartes centrais (CPCs) são entidades que atuam como compradoras para todo vendedor e como vendedoras para todo comprador numa série (específica) de 
contratos. Se uma parte não honrar sua obrigação, a contraparte central o faz, ficando a seu cargo depois a cobrança da parte inadimplente. Este arranjo permite reduzir o chamado risco de crédito de contraparte, muito embora concentre um número grande de operações num mesmo agente - a contraparte central. Para reduzir os riscos, contudo, as CPCs comumente utilizam requerimentos de margem e garantias e a criação de fundos de recursos a serem usados no caso de default das partes.

A utilização destas entidades também foi uma das principais soluções adotadas para mitigar os riscos do mercado de derivativos de balcão. A reforma regulatória deste segmento impôs uma série de novas obrigações aos participantes de mercado: o registro dos derivativos em infraestruturas especializadas (repositórios de negócios) passou a ser obrigatório (antes os registros eram de responsabilidade das próprias instituições financeiras e das demais contrapartes); buscou-se adotar medidas que levassem à maior padronização dos contratos; os contratos padronizados seriam levados, obrigatoriamente, à liquidação em contrapartes centrais; requerimentos de margem passaram a ser exigidos dos contratos não liquidados através de CPCs; criou-se redução dos requerimentos de capital para contratos liquidados em CPCs, como forma de induzir os agentes a preferir estas operações (FSB, 2010, 2011).

$\mathrm{O}$ aumento da transparência do mercado de derivativos de balcão foi uma importante medida para que as autoridades fossem capazes de avaliar os reais riscos aos quais as instituições financeiras estavam sujeitas. O caso da quebra do banco Lehman Brothers foi emblemático, pois a instituição deixou de honrar uma série de contratos derivativos, com impactos em diversos mercados. Antes da quebra, as exposições que o banco acumulou não eram sequer visíveis às autoridades, pois a opacidade das transações fazia parte das regras do mercado. Lançar luz sobre a intrincada rede de exposições originadas por contratos derivativos, portanto, jogou os holofotes sobre os mecanismos de externalização de risco utilizados pelas instituições.

Por fim, outra forma encontrada pelos reguladores para iluminar esta área foi a atualização e ampliação da base de apuração dos requerimentos bancários, isto é, o conceito de conglomerado financeiro utilizado no Acordo de Basileia. A criação de entidades parente não financeiras - sociedades ou veículos de propósito específico - foi uma saída amplamente utilizada para externalizar alguns riscos no período pré-crise, tirando dos balanços dos bancos exposições relevantes, que depois rebateram sobre estas instituições. Com Basileia III, a base de apuração dos requerimentos de capital (e de liquidez e alavancagem) e a incidência dos padrões de gerenciamento de risco passaram a abarcar não só os bancos e instituições assemelhadas, mas incluíram também uma série de instituições antes ausentes, como forma de evitar as práticas mencionadas.

Para fins de ilustração, podemos comparar os conceitos de conglomerado financeiro (Basileia II) e conglomerado prudencial (Basileia III) utilizados pelo Conselho Monetário Nacional (CMN) brasileiro. Em Basileia II, os requerimentos eram apurados agregando as "entidades financeiras vinculadas diretamente ou não, por participação acionária ou por controle operacional efetivo, caracterizado pela administração ou gerência comum, ou pela atuação no mercado sob a mesma marca 
ou nome comercial”. Após a introdução de Basileia III, a base passou a ser: as instituições financeiras e assemelhadas; administradoras de consórcio; instituições de pagamento; sociedades que realizem aquisição de operações de crédito, inclusive imobiliário, ou de direitos creditórios, a exemplo de sociedades de fomento mercantil, sociedades securitizadoras e sociedades de objeto exclusivo; sociedades seguradoras, resseguradoras, de capitalização e entidades abertas de previdência complementar (neste último caso, fundos de pensão); outras pessoas jurídicas que tenham por objeto social exclusivo a participação societária nas entidades mencionadas anteriormente (Resolução $\mathrm{n}^{\circ} 4.280$, de 2013, do CMN) ${ }^{3}$.

A comparação deixa clara a maior amplitude e especificidade do conceito de conglomerado prudencial. A partir desta mudança, as instituições serão responsáveis por apurar e gerenciar os riscos neste nível, portanto englobando mais entidades e exposições. Isto teria por objetivo dificultar a ocultação de riscos dos olhos dos reguladores e, potencialmente, reforçar a segurança do sistema.

\section{LIMITES À ALAVANCAGEM}

O sistema financeiro globalizado se consolidou em meio a uma escalada vertiginosa da alavancagem. Torres (2014: 446) utiliza uma citação de Goodhart (2009) para ilustrar que vários importantes bancos globais operavam com uma elevada razão de alavancagem, próxima de 50 para 1, sobre seu capital - destaca, em particular, UBS, Deustche Bank e Barclay's. Tal patamar de alavancagem resultou do novo modelo de negócios das instituições, da utilização de veículos fora de balanço, para mascarar as verdadeiras exposições das instituições ou simplesmente "externalizar" os riscos, e das estreitas relações com fundos de hedge (e também fundos de private equity).

Estas condições de operação geraram uma capacidade monumental de expansão dos ganhos das instituições (e, assim, do tamanho delas próprias), mas expuseram o sistema como um todo a um grau de fragilidade substancial. Como aponta Torres (2014: 446): "Com tais níveis de alavancagem, perdas menores perante o ativo total dessas instituições podem ter efeitos catastróficos sobre sua solvência e, consequentemente, sobre a estabilidade sistêmica do sistema financeiro global". Ainda, o autor destaca que isso "explica por que os prejuízos acumulados em uma parcela pequena do mercado imobiliário americano - o subprime - colocaram em xeque instituições consideradas tão robustas e até mesmo conservadoras”.

A resposta no nível do G20 indicava que a regulação deveria prevenir a alavancagem excessiva e requerer a acumulação de colchões de recursos em tempos de prosperidade. Neste âmbito, o Comitê de Basileia ficou responsável por rever as regras de capitalização das instituições financeiras, demandando mais capital, de

\footnotetext{
${ }^{3}$ Inclui entidades, localizadas no Brasil ou no exterior, sobre as quais a instituição detenha controle direto ou indireto.
} 
maior qualidade ${ }^{4}$, introduzindo requerimentos anticíclicos de capital e ampliando as bases de apuração dos requerimentos para incluir exposições a entidades fora de balanço, como descrevemos na seção anterior. Ainda, instituições consideradas sistemicamente importantes, tanto em nível global como nacional, passaram a ser obrigadas a manter níveis de capitalização superiores aos das instituições ordinárias.

Somou-se a estes esforços a criação de um novo elemento regulatório, a introdução de um limite absoluto de alavancagem, conhecido por razão de alavancagem (leverage ratio). Esta seria uma medida suplementar aos já tradicionais requerimentos de capital e aos novos requerimentos de liquidez de curto e longo prazos introduzidos por Basileia III. A razão estabelece um limite para a relação entre o capital da instituição e a soma total de suas exposições, isto é, seu ativo (no nível do conglomerado prudencial).

O limite mínimo que as instituições devem observar é inicialmente de $3 \%$, o que permite uma alavancagem de 33 vezes o capital - valor elevado, porém inferior ao patamar de 50 para 1 de algumas instituições no pré-crise. Cabe notar que é um valor tentativo, seja porque é um índice novo, cujo monitoramento ainda é desconhecido por reguladores do mundo todo, seja devido à situação ainda anêmica da economia mundial. O Comitê de Basileia se comprometeu a avaliar a adequação deste valor em 2017.

Os exercícios de impacto quantitativo realizados pela Autoridade Bancária Europeia (EBA) sobre a evolução da razão de alavancagem na região mostra que já houve um processo de redução da alavancagem significativo. Ao passo que no primeiro semestre de 2011 as grandes instituições financeiras europeias apresentavam um indicador na casa de $2,9 \%$, mostrando a necessidade de capitalização adicional ou de redução das exposições, no primeiro semestre de 2015 este indicador alcançava, em média, o valor de 4,7\% para instituições do mesmo grupo, patamar significativamente superior aos 3\% exigidos (EBA, 2011; 2016). Cerutti e Claessens (2014) mostram que este processo de redução da alavancagem se replica nos bancos atuantes globalmente em geral.

Outro fator que poderia contribuir para limitar a alavancagem do sistema é a limitação das relações dos bancos com fundos de hedge prevista pela Regra de Volcker e regras de separação europeia e britânica. A utilização destes veículos como forma de operar os negócios bancários e para gerir o capital próprio das instituições passou a contar com um importante limitador a partir das novas regras. Além disso, os novos padrões de limitação à reutilização de garantias e o maior monitoramento das operações de fundos de hedge devem também influenciar esta conta.

Dos elementos descritos acima podemos inferir um quarto fato estilizado, qual

\footnotetext{
${ }^{4}$ Por capital de maior qualidade entende-se, basicamente, lucros acumulados e capital social. Há uma clara rejeição de passivos híbridos e dívidas subordinadas a cujo acesso em tempos de dificuldade pode ser mais complicado. Inclusive, houve um aprimoramento nas condições dos instrumentos de dívida subordinada que podem integrar o capital das instituições. Ver Comitê de Basileia (2010).
} 
seja, a tendência à desalavancagem introduzida pela regulação pós-2008. Neste novo cenário, as possibilidades de expansão das instituições encontram-se constrangidas por novas amarras regulatórias.

\section{UMA PERSPECTIVA CRÍTICA: HELLEINER E A CRISE DO STATUS QUO}

A descrição sobre as ações regulatórias do pós-crise realizada nas seções anteriores buscou ressaltar as mudanças almejadas e seus impactos esperados, ressaltando o caráter transformador que as medidas poderiam exercer - ou exerceram - sobre os processos estruturantes do sistema financeiro global. Tal perspectiva, contudo, não é consensual. Outros autores que analisaram o tema sustentam uma análise mais crítica das reformas, em separado ou em sua totalidade (Leite e Reis, 2013; Carvalho, 2014; Helleiner, 2014; Pagliari, 2015; Helleiner et al., 2018).

Dentre os trabalhos mencionados, a contribuição de Helleiner (2014), o livro “The Status Quo Crisis”, se destaca por apresentar uma abordagem totalizante, não fragmentária, sobre a temática. Essa perspectiva é a que mais se assemelha ao olhar de Torres (2014) e à abordagem do presente artigo, funcionando, portanto, como uma espécie de contraponto à análise até aqui desenvolvida ${ }^{5}$.

Helleiner (2014) apresenta uma interpretação crítica sobre as mudanças efetivas que a crise de 2008 e os acontecimentos subsequentes representaram para a governança financeira global e a configuração do sistema financeiro globalizado. Segundo a interpretação do autor, a crise em questão não implicou uma ruptura, portanto, não foi um evento transformador. Ela teria sido um "evento estranhamente conservador", um evento de manutenção do status quo (Helleiner, 2014: 8).

$\mathrm{O}$ autor sustenta sua tese com base na análise de quatro desenvolvimentos que ocorreram após a crise: (i) a criação do G20 e seu papel de liderança na governança global; (ii) os questionamentos sobre o papel do dólar como a principal moeda internacional; (iii) as reformas regulatórias que, em sua concepção, promoveriam um viés antimercado nos padrões internacionais; (iv) a criação do Financial Stability Board (FSB), como um quarto pilar da arquitetura econômica global ${ }^{6}$.

A análise de Helleiner conclui que a criação do G20 e do FSB e o papel que estes organismos desempenharam foram menos significativos que o esperado e propagado (Helleiner, 2014: Capítulos 2 e 5, respectivamente). A hierarquia monetária global praticamente não sofreu mudanças, tendo o dólar mantido seu papel hegemônico no sistema monetário e financeiro internacional (Helleiner, 2014: Capítulo 3). Por fim, quanto às mudanças regulatórias, o autor argumenta que elas

\footnotetext{
${ }^{5}$ Os demais trabalhos enfocam aspectos específicos das mudanças regulatórias, como Basileia III (Leite e Reis, 2013; Carvalho, 2014) ou o mercado de derivativos (Helleiner et al., 2018), ou discutem genericamente a regulamentação (e.g. Pagliari, 2015) sem analisar seus efeitos sobre o sistema em si.

${ }^{6}$ Os outros três pilares seriam o Fundo Monetário Internacional, o Banco Mundial e a Organização Mundial do Comércio (Geithner, 2009).
} 
ficaram muito aquém do esperado quando a crise eclodiu, mantendo intacto o viés pró-mercado vigente no período pré-crise.

Este último ponto merece maior detalhamento. Quanto à regulação bancária, o autor argumenta que Basileia III trouxe mudanças, mas não atacou pontos fundamentais: o novo acordo continuou a permitir que os bancos usassem modelos próprios de avaliação de riscos; os requerimentos de capital, embora maiores, não eram superiores aos níveis praticados por diversas instituições que enfrentaram problemas durante a crise; a razão de alavancagem, no nível fixado (3\%), não representaria uma limitação relevante à expansão dos balanços dos bancos; dentre outros elementos (Helleiner, 2014: 82-3).

Helleiner (2014: 86-7) critica também o foco da regulamentação das agências de avaliação de risco (rating) e dos fundos de hedge, situado meramente sobre o registro dessas entidades e a divulgação de informações para as autoridades regulatórias. Embora os novos padrões sujeitem tais instituições a alguma supervisão, não há nenhuma definição quanto aos padrões de avaliação dos riscos no caso das agências de rating ou limites prudenciais para os fundos de hedge.

No caso do mercado de derivativos, a avaliação do autor é de que as regulações adotadas abriram possibilidades de arbitragem regulatória devido à forma e aos termos adotados, que permitiriam aos agentes explorar eventuais lacunas e adotar interpretações que os favorecessem (Helleiner, 2014: 89). Além disso, destaca que medidas como a proibição de determinados tipos de derivativos ou a restrição à negociação de derivativos de crédito mediante a posse dos ativos subjacentes não fizeram parte do rol de mudanças (idem: 90 ).

A partir desses pontos, Helleiner (2014: 97-8) conclui que:

the G20 leaders certainly deserved applause for tackling a wide range of issues in their efforts to reform international regulatory standards. But the content of the reforms endorsed by the G20 fell well short of the predictions of transformative change made when the crisis began [...] Rather than turning their back on the 'market-friendly' nature of the pre-crisis international financial regulatory regime, the G20 leaders merely tweaked its content.

A interpretação crítica de Helleiner não é, contudo, integralmente incompatível com a análise levada a cabo nas seções anteriores do presente artigo. As perspectivas desse autor sobre os efeitos das mudanças sobre o modus operandi do sistema financeiro global são pouco favoráveis: para ele, esses efeitos são praticamente nulos. Contudo, acredita-se ser possível compatibilizar as duas leituras.

As mudanças regulatórias perpetradas pelo G20 e pelos reguladores nacionais, em sua essência, não teriam buscado alterar de forma substancial a configuração e a forma de operar do sistema financeiro global, mas acabaram por afetar seus elementos estruturantes, criando novas bases de operação do sistema.

O principal ponto das reformas foi adicionar amarras ao sistema, que, conforme a análise de Helleiner, podem até se revelar insuficientes, mas que antes eram 
completamente inexistentes. A influência dessas medidas trouxe novos custos - por exemplo, o custo de liquidação centralizada dos derivativos de balcão - antes ausentes, introduziu novos padrões de gerenciamento dos riscos, gerou maior fragmentação dos mercados e acarretou mudanças nos modelos de negócio das instituições financeiras.

A maior complexidade do novo ambiente regulatório também teve impactos sobre o ajuste dos mercados financeiros, especialmente, num contexto de taxas de juros próximas a zero. Um exemplo é o efeito que as medidas de restrição à negociação proprietária e o ringfencing vêm tendo sobre o papel dos bancos como criadores ou fazedores de mercado (market-makers) nos diversos segmentos dos mercados financeiros (Duffie, 2012). Mesmo a função dos bancos como dealers sofreu alterações. Como ilustram Choi e Huh (2017) no caso do mercado norte-americano de títulos corporativos, a provisão de liquidez se moveu para agentes que não atuavam como dealers de mercado e os custos de transação se eleveram: "increase in transaction costs are consistent with the Volcker Rule and more stringent capital regulations having affected liquidity in the OTC markets" (Choi e Huh, 2017: 26).

Outro exemplo é fornecido por Pozsar (2016a, 2016b, 2017), que argumenta que os mercados monetários passaram a funcionar de modo distinto ao que funcionam no período pré-crise em função da conjunção das políticas monetárias não convencionais (quantitative easing) e das medidas de Basileia III, em particular, devido aos novos requerimentos de liquidez. Uma consequência dessas mudanças diz respeito à dificuldade de operacionalização da política monetária através da definição da taxa básica de juros pelo Federal Reserve Bank norte-americano - no novo ambiente, esta pouco influenciaria as estruturas de preço dos diferentes mercados.

Nesse sentido, é possível admitir que as mudanças regulatórias foram menos disruptivas do que poderiam ter sido e, ao mesmo tempo, reconhecer a possibilidade de que geraram alterações para o funcionamento e as bases de expansão do sistema financeiro globalizado.

\section{CONSIDERAÇÕES FINAIS}

A descrição e o detalhamento das mudanças regulatórias trazidas pelas reformas pós-2008 ao longo das últimas seções buscaram explicitar como elas afetaram os processos estruturantes do sistema financeiro globalizado contemporâneo. Buscamos reunir evidências de que os processos que antes configuraram a base para a expansão do sistema financeiro global não estão, ao menos em sua plenitude, mais presentes após a crise financeira internacional.

A liberalização dos mercados financeiros característica do período anterior deu lugar a uma ampla agenda de "re-regulação" coordenada pelo G20 em âmbito internacional e implantada pelas jurisdições que contam com as mais importantes instituições e sistemas financeiros do mundo. Como afirmamos, a orientação pós-crise se deu no sentido de um maior rigor regulatório e de criação de amarras à operação do sistema financeiro global, ainda que, como argumenta Helleiner 
(2014), esse rigor não tenha sido tão elevado quando o desejado ou sugerido no momento mais agudo do debacle.

Em segundo lugar, o processo de desintermediação bancária consubstanciado na mudança no modelo de negócios dos bancos passou por constrangimentos significativos. As regras de proibição ou separação do trading proprietário e das relações com fundos de hedge, bem como os novos custos regulatórios introduzidos, criam as bases para uma nova redefinição do modelo de negócios bancário, mais compartimentalizado, mais restritivo e mais balcanizado. Como apontamos, podemos indicar certa "re-segmentação" e "re-nacionalização" dos bancos como produtos das mudanças regulatórias pós-2008.

Do ponto de vista da externalização do risco, as medidas regulatórias visaram a ampliar as margens de segurança com as quais o sistema trabalha e limitar a capacidade de arbitragem regulatória dos bancos em relação a seus balanços. Os mercados de securitização, empréstimo de títulos, operações compromissadas e derivativos serão obrigados a conviver com padrões mais rígidos de gerenciamento de risco. Os requerimentos de retenção de risco e a utilização de contrapartes centrais ganham particular destaque neste processo. Se não é possível falar em "re-intermediação" das transações, pelo menos podemos contar com constrangimentos ao processo de desintermediação vivido no pré-crise.

Em quarto lugar, a expansão do sistema baseada na alavancagem passou a contar com um importante freio através da imposição de limites, diretos ou indiretos, de alavancagem aos bancos. Um processo de desalavancagem das instituições financeiras vem sendo testemunhado desde a eclosão da crise, sendo em parte explicado pelos novos padrões regulatórios.

Portanto, a partir destes elementos, podemos concluir que o sistema financeiro global encara hoje uma estrutura distinta daquela que contribuiu para sua consolidação, bem como houve alterações, porém, até o momento, de menor importância, em seu modus operandi. Com efeito, as reformas regulatórias implementadas a partir da crise financeira internacional de 2008 influenciaram diretamente cada um dos processos estruturantes da globalização financeira. Afirmamos, assim, que os caminhos de expansão do sistema financeiro global foram redefinidos após a crise. Ainda não é possível delimitar novas trajetórias, embora seja possível tecer alguns comentários sobre o processo de reforma regulatória, seu alcance e seus limites.

A afirmação de Torres (2014: 448) é pertinente: “A imposição de limitações mais severas às estratégias de negócios dos bancos e de outras instituições sistemicamente esbarra, no entanto, em grandes dificuldades". A senadora (democrata) americana Elizabeth Warren vem há alguns anos lançando luz sobre as tentativas conduzidas por participantes do mercado financeiro de minar a reforma regulatória programada. Como destacado em um discurso em 2015:

The biggest financial institutions aren't just big - they wield enormous political power. Last December, Citibank lobbyists wrote an amendment to Dodd-Frank and persuaded their friends in Washington to attach it to a bill that had to pass or the government would have 
been shut down. And when there was pushback over the amendment, the CEO of JPMorgan, Jamie Dimon, personally got on the phone with Members of Congress to secure their votes. How many individuals who are looking for a mortgage or a credit card could make that call? How many small banks could have their lobbyists write an amendment and threaten to shut down the US government if they didn't get it? None. Keep in mind that the big banks aren't trying to make the market more competitive; they just want rules that create more advantages for themselves. The system is rigged and those who rigged it want to keep it that way. (Warren, 2015)

Se foi a estruturação de um sistema financeiro globalizado, liberalizado e alavancado que permitiu a estas instituições auferir lucros inéditos na história econômica mundial, não é de se esperar que as instituições reajam de forma passiva às mudanças pretendidas pelos reguladores. Por outro lado, a crise de 2008 deixou claro que o sistema precisa de alguns freios, do contrário os efeitos deletérios podem tomar proporções inimagináveis - a longa recessão mundial é ilustrativa destas proporções.

Assim, numa primeira leitura, nos parece que as mudanças regulatórias operaram efetivamente para alterar as bases do sistema, porém não atacam alguns aspectos fundamentais, como a diminuição do tamanho das instituições, para ficar num só exemplo - ver Helleiner (2014: Capítulo 4) para outros. Acredita-se que o sistema financeiro globalizado terá seu modus operandi alterado de forma menos pronunciada, porém não irrelevante: o que ocorre é que existirão algumas amarras que irão impedir a expansão desenfreada das instituições globais para fins de segurança do sistema; outras mudanças decorrerão da redefinição do papel dos grandes bancos globais como dealers e market-makers em diversos mercados (títulos corporativos, derivativos etc.), o que, contudo, só ficará mais claro após a normalização das taxas básicas de juros dos principais bancos centrais, em especial, o norte-americano. Neste sentido, o sistema financeiro globalizado que emergirá após todas as mudanças citadas se consolidarem será um sistema mais regulado, menos opaco, mais segmentado e menos alavancado. Portanto, mais seguro, relativamente, porém similar em sua essência.

Tal afirmativa não impede que formulemos algumas questões importantes, de difícil resposta: Como o espaço concorrencial das instituições financeiras será afetado ou redefinido pelas novas regulações? É difícil imaginar que os Estados Unidos (e o dólar) percam a centralidade do sistema financeiro global, porém é possível imaginar deslocamentos ou a criação de forças centrípetas regionais, em particular na Ásia e na América Latina? Talvez o principal espaço de observação do prognóstico do parágrafo anterior seja a evolução dos sistemas financeiros dos países em desenvolvimento e subdesenvolvidos, que poderão revelar como as novas vertentes irão condicionar sua expansão. Até a próxima crise financeira de proporções globais. 


\section{REFERÊNCIAS BIBLIOGRÁFICAS}

Anbima. (2012). "Europa discute unificação bancária e ring-fencing”. Radar Anbima n 3. Rio de Janeiro: Anbima.

Anbima (2013). “FSB divulga suas recomendações de políticas para o shadow banking system”. Radar Anbima ${ }^{\circ}$ 4. Rio de Janeiro: Anbima.

Comitê de Basileia. (2010). Basel III: A global regulatory framework for more resilient banks and banking systems. Basileia: Bank for International Settlements, dezembro.

Comitê de Basileia.. (2012). Revisions to the Basel Securitisation Framework: Consultative Document. Basileia: Bank for International Settlements, dezembro.

Bloomberg. (2016). “Citigroup Latin America Sale Seen Tempting Locals, Santander”. Matéria de 19 de fevereiro.

Business Insider UK. (2015). “BY THE NUMBERS: Here's what you need know about HSBC's money-laundering and tax-evasion scandals". Matéria de 18 de fevereiro.

Canuto, O.; Ramcharan, V. (2015). “De-Risking Is De-linking Small States from Global Finance”. Huffington Post, matéria de 22 de outubro.

Carvalho, F. J. C. (2014). “Can Basel III Work When Basel II Didn't?” In: Papadimitriou, D. (ed.) Contributions to Economic Theory, Policy, Development and Finance: Essays in Honour of Jan A. Kregel. New York: Palgrave Macmillan.

Cerutti, E.; Claessens, S. (2014). “The Great Cross-Border Bank Deleveraging: Supply Constraints and Intra-Group Frictions”. IMF Working Paper 14/80. Disponível em: https://www.imf.org/external/ pubs/ft/wp/2014/wp14180.pdf.

Choi, J.; Huh, Y. (2017). "Customer Liquidity Provision: Implications for Corporate Bond Transaction Costs”. FEDS Working Paper No. 2017-116. Disponível em: http://dx.doi.org/10.17016/FEDS.2017.116.

Duffie, D. (2012). "Market making under the proposed Volcker rule”. Stanford Graduate School of Business Working Paper $n^{\circ} 3118$.

EBA. (2011). Results of the Basel III monitoring exercise as of 30 June 2011. Bruxelas: EBA.

EBA. (2016). CRD IV - CRR/Basel III Monitoring Exercise: results based on data as of 30 June 2015. Bruxelas: EBA.

Financial Times. (2011). "Santander sells Colombian unit for \$1.2bn". Matéria de 7 de dezembro.

FMI. (2011). Recent Experiences in Managing Capital Inflows: Cross-Cutting Themes and Possible Policy Framework. IMF Research Report prepared by the Strategy, Policy, and Review Department.

FSB. (2010). Implementing OTC Derivatives Market Reforms. Basel: FSB, Outubro.

FSB. (2011). OTC Derivatives Market Reforms: Progress Report on Implementation. Basel: FSB, Abril.

G20. (2008). Declaration of the Summit on Financial Markets and the World Economy. Washington, D.C.: G20.

G20. (2009). Global Plan for Recovery and Reform. Statement Issued by the G20 Leaders. Londres: G20.

G30. (2009). Financial Reform: A Framework for Financial Stability. Washington, D.C.: The Group of Thirty (G30).

Geithner, T. (2009). Press Briefing by Treasury Secretary Tim Geithner on the G20 Meeting. Pittsburgh Convention Center, September 24. TG-405. Disponível em: https://www.treasury.gov/press-center/press-releases/Pages/tg405.aspx.

Goodhart, C. (2009). "Financial Crisis and the Future of the Financial System". 100th BRE Bank-CASE Seminar, Warsaw.

Helleiner, E. (2014). The Status Quo Crisis: Global Financial Governance After the 2008 Meltdown. New York: Oxford University Press.

Helleiner, E.; Pagliari, S.; Spagna, I. (eds.) (2018). Governing the World's Biggest Market: The Politics of Derivatives Regulation After the 2008 Crisis. Oxford University Press.

Iosco. (2012). Global Developments in Securitisation Regulation. Madrid: Iosco. 
Isda. (2014). Cross-Border Fragmentation of Global OTC Derivatives: An Empirical Analysis. ISDA Research Note, janeiro.

Isda.. (2015). Cross-Border Fragmentation of Global Interest Rate Derivatives: The New Normal? ISDA Research Note, outubro.

Kregel, J. (2008). “Minsky's Cushions of Safety: Systemic Risk and the Crisis in the U.S. Subprime Mortgage Market”. Economics Public Policy Brief n ${ }^{\circ}$ 93. Levy Economics Institute.

Leite, K. V.; Reis, M. (2013). “O Acordo de Capitais de Basiléia III: Mais do Mesmo?”. Revista EconomiA, Vol. 14, n ${ }^{\circ}$ A: 159-87.

Pagliari, S. (2015). "Financial industry power and regulatory policies: What lessons from the global financial crisis?” Rivista Italiana di Politiche Pubbliche, Vol. 10, $\mathrm{n}^{\circ}$ 2: 209-32.

Pozsar, Z. (2016a). “What Excess Reserves?”. Global Money Notes no 5. Credit Suisse, Economic Research.

Pozsar, Z.. (2016b). “QE, Basel III and the Fed's New Target Rate”. Global Money Notes nº 6. Credit Suisse, Economic Research.

Pozsar, Z.. (2017). "Excess Reserves and Global Dollar Funding”. Global Money Notes n 9. Credit Suisse, Economic Research.

Pozsar, Z.; Adrian, T.; Ashcraft, A.; Boesky, H. (2010). “Shadow Banking”. Federal Reserve Bank of New York Staff Report No. 458. Nova Iorque: Federal Reserve Bank of New York.

Reuters. (2015). "Bradesco to acquire HSBC Brazil unit, biggest-ever buy”. Matéria de 3 de agosto.

Torres Filho, E. (2014). “A crise do sistema financeiro globalizado contemporâneo”. Revista de Economia Política, Vol. 34, no 3 (136): 433-50, julho-setembro.

Wall Street Journal. (2015). “HSBC Struggles in Battle Against Money Laundering”. Matéria de 12 de janeiro.

Warren, E. (2015). “The Unfinished Business of Financial Reform”. Remarks at the Levy Institute's 24th Annual Hyman P. Minsky Conference, April 15, 2015. 